\title{
Influence Of Negative Life Events On Depression Among In- School Adolescents In Southwest Nigeria
}

\author{
Dr. Ibimiluyi Francis Olu \\ Dept of Guidance and Counselling, Faculty of Education, \\ Ekiti State University, Ado Ekiti \\ Dr. Fasina Bosede Oluwayemisi \\ Dept of Guidance and Counselling, Faculty of Education, \\ Ekiti State University, Ado Ekiti \\ Dr Iretor-Oscar Oluwaseun Bamidele \\ Dept of Guidance and Counselling, Faculty of Education, \\ Ekiti State University, Ado Ekiti
}

\begin{abstract}
This study investigated the influence of various negative life events on adolescent depression among in-school adolescents in Southwest Nigeria and whether there is gender difference in the association. The descriptive research of the survey type was adopted for the study. The population of the study was all the adolescents, both male and female, in all secondary schools in the southwest of Nigeria. A total of 1650 adolescents between the ages of 12 and 18 years were selected using multistage sampling technique. A self designed questionnaire titled "Assessment of Negative Life Events and Depression Scale" (ANLEDS) was used to elicit information from respondents. The instrument was validated and the reliability was ensured using test re-test method. The reliability co-efficient was 0.75 at 0.05 level of significance. The data collected were analyzed using descriptive analysis for the general question raised while hypotheses 1 was tested using Pearson Product Moment Correlation and hypotheses 2 was tested using student's t-test at 0.05 level of significance. The result showed that negative life experiences are significantly related to the development of depressive symptoms among adolescents and the association is influenced by gender difference. Based on the findings, it was recommended that school counsellors should organize programmes to create more awareness and encourage adolescents to discuss their challenges with a view to reducing adolescent depression in Southwest Nigeria.
\end{abstract}

Keywords: negative life events, adolescent depression, gender, in-school adolescents, counselling intervention 


\section{INTRODUCTION}

Adolescent depression has long been regarded as one of the most occurring serious psychiatric disorders (WHO, 2010; Zuckerbrot, et al., 2018) and it has been ranked as the fourth leading cause of disability and premature death among the adolescents, worldwide (Hankin, 2006). It is not quite different from adult depression as it is also characterized by a combination of symptoms highlighted in DSM-5 to include change in mood, physical symptoms like changes in sleep, energy and appetite, feelings of worthlessness, concentration difficulties and a person's degree of confidence (American Psychological Association, 2013). In essence, depression occurs when the adolescent's depressed mood or a loss of interest or pleasure in daily activities is notified and persisted for more than two weeks.

Depression may start in the adolescence or even earlier. Meanwhile, the prevalence rate of adolescent depression has been on the increase in recent years (Bertha \& Balazs, 2013), and the age of onset has been decreasing (Fombonne, 1994). If not well managed at this stage, it may later become one of the important causes of mental illness in adulthood. Researchers have found out that various development challenges arising from peer pressure (Platt, Kadosh, \& Lau, 2014; Moksnes, Espnes \& Haugan, 2014), academic expectations (Ma, Siu, \& Tse, 2018), changing bodies (Siegel, 2002) and family issues (Kim, \& Cain, 2008), among others, can bring a lot of ups and downs for teens which may lead to the development of depression among the adolescents.

Most adolescents, especially in the Southwest Nigeria, have been exposed to different social, psychological and developmental challenges in the cause of their various interactions and these might have built up some stresses on them. Experience shows that life for many adolescents in Nigeria is a tug of war filled with mixed messages and conflicting demands from parents, teachers, friends, oneself and the constituted authorities. Growing up to fit in well and express oneself effectively and efficiently in this social environment might not be an easy task for the growing youth. It is not uncommon for either absence of positive or presence negative life events in the social environment to become a crisis that might precede the development of depression among adolescents (Hammen, 2005). In other words, stress occasioned by the negative life events might play a significant role in determining vulnerability of adolescents to depression. Sources of stress to most adolescents in Southwest Nigeria might include poor academic performance, loss of a loved one (father or mother), strained relationships with parents, change in the parents' financial status; break up of a romantic relationship, prolonged illness, living in an unsafe neighborhood, and so on (Kio, Omeonu \& Agbede, 2015). Interaction with some youths who face these challenges in counselling sessions, show that such challenge might predispose them to depression.

Some of the in-school adolescents seem to respond to these stressful situations by doing positive things which might help them to relax and overcome the stressful situation such as seeking support from significant others (parents, teachers and peers) characteristic of an African social environment, engaging in behaviors such as listening to good music, watching television programmes, engaging in spiritual activities in their places of worship, engaging in sporting activities, and so on. However, many of them are not as lucky as the stressors continue to pile up making them to become less inclined to things they were used to doing, not interested in school or home activities. They might even attempt to or run away from home or school, experience feelings of shame, failure or unworthiness, and so on. Others might even be thinking of committing suicide. Such behaviours are symptoms of depression. 
Ibimiluyi, F. O., Fasina, B. O. \& Iretor-Oscar, O. B. (2020) Influence Of Negative Life Events On Depression Among In-School Adolescents In Southwest Nigeria. Advances in Social Sciences Research Journal, 7(5) 430-439.

The association between stressful life events and depression has been consistently supported in the literature (Kessler, 1997; Johnson, Whisman, Corley, Hewitt, \& Rhee, 2012) as there are evidences that support a strong association between major life events and the subsequent onset of Major Depressive Disorder (MDD). Examples of such life events include academic stress (Deb, Strodi, \& Sun, 2014), life stress (Hammen, 2005; Monroe \& Reid, 2009; Johnson, Whisman, Corley, Hewitt, \& Rhee, 2012), physical illness of a parent (Barkmann, Romer, Watson, \& Schulte-Markwort, 2007), parental psychiatric illness (Rutter \& Quinton, 1984), parental substance use (Hanson, Self-Brown, Fricker-Elhai, Kilpatrick, Saunders \& Resnick, 2006) family breakdown (Amato, 2001), parental conflict (Herrenkhol, Kosterman, Hawkins \& Mason, 2009; Weymouth, Buehler, Zhou, \& Henson, 2016) and early parenthood (Hofferth \& Reid (2002) among others.

Of note in Southwest Nigeria is the influence of loss of close relations. Meanwhile, studies have shown that interpersonal loss has a strong association with the development of depression (Slavich, 0’Donovan, Epel, \& Kemeny, 2010a). Stressors involving interpersonal loss, for example, are the most common precipitant of depression, with $44 \%$ of depressive episodes being preceded by such stress (Farmer \& McGuffin, 2003). In addition, the work of Kendler, Hettema, Butera, Gardner, and Prescott (2003) have found that the risk for depression is greater following interpersonal loss than for any other type of major life event. Given these findings, Slavich, Monroe and Gotlib (2011) posit that persons at risk for depression may be more sensitive to stressors involving interpersonal loss (e.g., relationship breakups, deaths) than to other types of stressors (e.g., occupational or financial problems). In an attempt to establish an association between depressive symptoms and negative dependent life events from late childhood to adolescence, Johnson, Whisman, Corley, Hewitt, and Rhee (2012), observed that there are marked increases in both life stress and depressive symptoms which occur during the transition from childhood into adolescence. These might have arisen as a result of various developmental changes.

The above findings agree with the proposal of hopelessness theory of depression which states that a sufficient cause of depression is an expectation that highly desirous outcome will not occur or that highly aversive outcome will occur coupled with an expectation that no response in one's repertoire will likely change the likelihood of occurrence of the outcomes (Abramson, Seligman \& Teasdale (1978). In other words negative life events may be strongly associated with the development of depressive symptoms.

Although it might be that a majority of depressive disorders are associated with severely negative life events or experiences, Brown, Bifulco and Harris (1987) found that only about one in five occurrences of severely negative life events lead to depression. In other words there might be some variations among individual's response to these events. Meanwhile studies have also, shown that not every person exposed to stress will develop depression and it is critical to understand sources of individual differences in vulnerability to the pathogenic effects of stress (Heim, Newport, Mletzko, \& Miller (2008). Along this line, Kendler, Kessler, Walters, MacLean, Neale, Heath and Eaves (1995) found that, in adults, negative life events were most likely to lead to onset of major depressive disorder in individuals inferred to have a genetic liability to depression. In other words, genetic constitution of an individual is more potent to predispose an individual to depression instead of the individual's experiences. Also, a study conducted by Monroe and Harkness (2005) shows that an estimated $30 \%$ of first-onset depressive episodes and $60 \%$ of all recurrent episodes appear to develop in the absence of major forms of stress. As a result, it can be suggested that some individuals 
may be especially sensitive to the depression effects of stress and, consequently, develop depression in response to more minor forms of adversity.

In other studies, psychosocial and environmental stressors are known risk factors for depression (Hunter \&National Institute of Mental Health (NIMH), 2013). NIMH research has shown that stress in the form of loss, especially death of close family members or friends, can trigger depression in vulnerable individuals. Stressful life events may contribute to recurrent episodes of depression in some individuals, while in others depression recurrences may develop without identifiable triggers. Other NIMH research indicates that stressors in the form of social isolation or early-life deprivation may lead to permanent changes in brain function that increase susceptibility to depressive symptoms (Hunter \& NIMH, 1999).

Given the foregoing, the researchers are asking whether or not there is an association between negative life events and adolescent depression in Southwest Nigeria? This study therefore, investigated the influence of various negative life events on adolescent depression among in-school adolescents in Southwest Nigeria. It also examined the gender difference in the association between the negative life events and adolescent depression and whether counselling intervention will help to prevent adolescent depression in Southwest Nigeria.

Based on these, a research question is asked: Will counselling intervention help to prevent depression among adolescents in Southwest Nigeria? Also, the following null hypotheses were generated and tested at 0.05 level of significance:

1. There is no significant relationship between negative life events and depression among inschool adolescents.

2. There is no significant gender difference in the association between negative life events and depression among in-school adolescents.

\section{RESEARCH METHOD}

Descriptive research of the survey type was used for the study. This was considered appropriate because it focuses on the observation of the population. The population for the study consisted of all the adolescents, both male and female, in secondary schools in the Southwest of Nigeria, comprising of six states namely, Ekiti, Lagos, Ogun, Ondo, Osun and Oyo. The secondary schools used included all the government and privately owned schools as well as coeducational and noncoeducational schools in southwest zone of Nigeria. The ages of adolescents that participated in the study were between 12 - 18years. The sample for this study consisted of 788 boys and 837 girls. The method of selection was multistage sampling technique. The first stage involved the use of simple random sampling technique by balloting system to select three states out of the six states in Southwest Nigeria. The three states thus selected were Lagos, Oyo and Ekiti States. The second stage entailed the use of purposive selection to select the government owned and private owned secondary schools in the states. The third stage also involved the use of stratified simple random sampling technique to select the sample from the schools selected. In all, a total of 1625 adolescents participated in the study.

A self designed questionnaire titled "Assessment of Negative Life Events and Depression Scale" (ANLEDS) was used to elicit information from respondents. The questionnaire consisted of three sections A, B, C and D. Section A contained information on demographic characteristics of the 
Ibimiluyi, F. O., Fasina, B. O. \& Iretor-Oscar, O. B. (2020) Influence Of Negative Life Events On Depression Among In-School Adolescents In Southwest Nigeria. Advances in Social Sciences Research Journal, 7(5) 430-439.

respondents, such as sex, age, and location. Section B contained 15 items to elicit information on the negative life events the adolescents are exposed to and the total score was 30 . The responses were "Yes" or "No" option and scored 2 and 1 respectively. Total score obtainable is 30. Respondents that scored 15 and above were regarded as having experienced negative life events while those that scored below 15 were not. Section C is a modified form of Beck's Depression Inventory which has been found to have high validity rating of 0.77 and reliability of 0.93 among Nigerian sample (Farinde, 2013). It consisted of 21 groups of statements on different symptoms of depression such as sadness, pessimism, failure, loss of pleasure, guilty feeling, self-dislike and so on. Each statement is rated on a modified 4-point Likert Scale $1-4$, with the respondents picking which of the statements best describe the way he or she is feeling in recent time and the moment. Respondents were expected to pick just one out of the options. The items were summed up to form a total score of 84. Respondents were categorized as experiencing 'Low', 'Moderate' and 'High' levels of depression based on percentile formula. Low (21.00 - 27.97), Moderate (27.98 - 55.97) and High (55.98 - 84.00). The instrument was subjected to Face, Content and Construct validity. The reliability of the instrument was established using test re-test method and the reliability coefficient of 0.75 was found to be significant at 0.05 level of significance. Section D contained 5 items on counselling intervention and responses were on "Yes" and "No" basis. Yes was rated 2 while No was rated 1 . Frequency and percentages were used to ascertain the perception of respondents on the role of counselling on adolescent depression.

The instrument was administered to 1,700 respondents by the researcher and six trained research assistants but a total of 1,625 copies of the questionnaire were collected and collated at the end of the administration. The data generated was analyzed using descriptive and inferential statistics. The descriptive statistics which include frequency counts, percentages, mean and standard deviation were used to answer the question raised while Hypotheses 1 was tested using Pearson Product Moment Correlation and hypotheses 2 was tested using student's t-test. All the hypotheses were tested at 0.05 level of significance.

\section{RESULTS}

Table 1: Demographic Characteristics of the Respondents (age and gender)

\begin{tabular}{|c|c|c|c|c|}
\hline Gender & Age (minimum) & Age (maximum) & Mean & SD \\
\hline Male $(n=788)$ & 15 & 18 & 15.68 & 9.93 \\
\hline Female $(n=837)$ & 15 & 18 & 15.77 & 12.04 \\
\hline Total $(n=1625)$ & 15 & 18 & 15.71 & 10.99 \\
\hline
\end{tabular}

Research Question: Will counselling interventions help to reduce the symptoms of depression among in-school adolescents in Southwest Nigeria?

In answering the question, responses on item 1-5 in Section D of "Assessment of Negative Life Events and Depression Scale (ANLEDS)" were subjected to statistical analysis using frequency counts and percentages. The result is presented in Table 2. 
Table 2: Counselling Interventions and Adolescent Depression

\begin{tabular}{|c|c|c|c|c|c|c|c|c|}
\hline \multirow{2}{*}{ S/N } & ITEMS & \multicolumn{2}{|c|}{ YES } & \multicolumn{2}{|c|}{ NO } & \multicolumn{2}{c|}{ TOTAL } & \multirow{2}{*}{ MEAN } \\
\cline { 3 - 7 } & $\mathbf{F}$ & $\mathbf{\%}$ & $\mathbf{F}$ & $\mathbf{\%}$ & $\mathbf{F}$ & $\mathbf{\%}$ & ME \\
\hline 1. & $\begin{array}{c}\text { Do you think consulting a guidance counsellor would } \\
\text { help reduce depression among adolescents? }\end{array}$ & 1109 & 68.2 & 516 & 31.8 & 1625 & 100.0 & 1.68 \\
\hline 2. & $\begin{array}{c}\text { Do you think counselling services would help to reduce } \\
\text { depressive symptoms among adolescent in schools? }\end{array}$ & 1247 & 76.7 & 378 & 23.3 & 1625 & 100.0 & 1.77 \\
\hline 3. & $\begin{array}{c}\text { Do you think social supports from counsellors or } \\
\text { parents are important to the adolescents? }\end{array}$ & 1307 & 80.4 & 318 & 19.6 & 1625 & 100.0 & 1.80 \\
\hline 4. & $\begin{array}{c}\text { Do you think forming a strong relationship between the } \\
\text { counsellor and in-school adolescent would help to } \\
\text { reduce adolescent depression? }\end{array}$ & 995 & 61.2 & 630 & 38.8 & 1625 & 100.0 & 1.61 \\
\hline 5. & $\begin{array}{c}\text { Do you think establishment of Depression Awareness } \\
\text { Club is necessary in schools }\end{array}$ & 1083 & 66.6 & 542 & 33.4 & 1625 & 100.0 & 1.67 \\
\hline
\end{tabular}

Table 2 shows that 1109 respondents representing $68.2 \%$ of the total sample agree that consulting a guidance counsellor would help to reduce depression among adolescents while 516(31.8\%) disagree. $1247(76.7 \%)$ agree that counselling services would help to reduce depressive symptoms among adolescent in schools while 378(23.3\%) disagree. On whether social supports from counsellors or parents are important to the adolescents, $1307(80.4 \%)$ agree while $318(19.6 \%)$ disagree. Also, 995(61.2\%) agree that forming a strong relationship between the counsellor and adolescents would help to reduce adolescent depression while 630 (38.8\%) disagree. Furthermore, $1083(66.6 \%)$ respondents agree that establishment of Depression Awareness Club is necessary in schools while $542(33.4 \%)$ disagree.

Using a cut-off mean score of 1.50 for the rating scale, all the items had mean scores above the cutoff mean score. This implies that counselling interventions were important strategies to reduce depression as thought by the adolescents.

Hypothesis 1: Negative life experiences are not significantly related to depression among in-school adolescents.

In order to test the hypothesis, scores on negative life experiences and development of depressive symptoms among in-school adolescents were computed using Items 1 - 15 in Section B and 1-21 in Section C of "Assessment of Negative Life Events and Depression Scale (ANLEDS)" respectively. These scores were subsequently subjected to statistical analysis involving Pearson Product Moment Correlation at 0.05 level of significance. The result is presented in Table 3.

Table 3: Correlation Analysis between Negative Life Experiences and Depression among In-School Adolescents.

\begin{tabular}{l|c|c|c|c|c|c|}
\hline Variables & $\boldsymbol{N}$ & Mean & SD & $\boldsymbol{r}_{\text {cal }}$ & r table \\
\hline Negative life experiences & 1625 & 14.14 & 1.94 & \multirow{2}{*}{$0.291^{*}$} & \multirow{2}{*}{0.062} \\
\hline Depression among in-school adolescent & 1625 & 31.71 & 9.85 & & \\
\hline
\end{tabular}


Ibimiluyi, F. O., Fasina, B. O. \& Iretor-Oscar, O. B. (2020) Influence Of Negative Life Events On Depression Among In-School Adolescents In Southwest Nigeria. Advances in Social Sciences Research Journal, 7(5) 430-439.

The result in Table 3 reveals that negative life experiences are significantly related to the development of depressive symptoms among in-school adolescent $(r=-0.291, p<0.05)$. Though the relationship between negative life experiences and depression among in-school adolescents is very low and negative, it is however statistically significant at 0.05 level. The null hypothesis is rejected. This implies that negative life experiences are significantly related to depression symptoms among in-school adolescents.

Hypothesis 2: There is no significant gender difference in the association between negative life events and depression among in-school adolescents.

In order to test the hypothesis, scores relating to the incidence of depression among male and female in-school adolescents in relation to their negative life experiences were computed and compared for statistical significance using t-test statistics at 0.05 level of significance. The result is presented in Table 4.

Table 4: Student t-test Showing Gender Difference in the Association between Negative Life Events and Depression

\begin{tabular}{|c|c|c|c|c|c|c|}
\hline Variables & $\boldsymbol{N}$ & Mean & $\boldsymbol{S D}$ & $\boldsymbol{d} \boldsymbol{*}$ & \multirow{2}{*}{$\boldsymbol{t}_{\text {cal }}$} & \multirow{2}{*}{ table } \\
\cline { 1 - 4 } Male & 788 & 31.96 & 9.93 & \multirow{2}{*}{1623} & \multirow{2}{*}{$2.924^{*}$} & \multirow{2}{*}{1.960} \\
\hline Female & 837 & 33.56 & 12.04 & & & \\
\hline
\end{tabular}

${ }^{*} \mathbf{p}<\mathbf{0 . 0 5}$

Table 4 shows that $t_{\text {cal }}(2.924)$ is greater than $t_{\text {table}}(1.960)$ at 0.05 level of significance. The null hypothesis is rejected. This implies that there is significant gender difference in the association between negative life events and depression among in-school adolescents. Also, female adolescents had higher mean score of 33.56 than their male (mean=31.96) counterparts. This implies that the incidence of depression is higher among female adolescents.

\section{DISCUSSION}

The result showed that negative life experiences are significantly related to the development of depressive symptoms among adolescents. This is in agreement with the findings of Amato (2001), Hoffert and Reid (2002) and Barkman, Romer, Watson and Schulte-Markwort, (2007) which indicate strong association between negative life events and development of depressive symptoms. This is because negative life events such as death of either or both parents, parental conflicts or divorce, prolonged illness and failure in examinations among others are stressors that can engender susceptibility to depression. However, the work of Heim, Newport, Mletzko, Miller, \& Nemeroff (2008) revealed that not every person exposed to stress will develop depression as individuals react differentially to the effects of stressful events.

The result also revealed that there is significant gender difference in the association between negative life events and depression among in-school adolescents. This is consistent with various findings which found that depressive symptoms may be gender specific (Schuster, Mermelstein \& Wakschlag, 2013) and that gender differences in depressive symptoms appear to emerge in early adolescence (Nolen-Hoeksema, Larson \& Grayson, 1999; Ryba, Derek \& Hopko, 2012; Gesinde \& Sanu, 2014). These might have arisen from the differential responses to various negative life experiences, life stress and challenges, pubertal transitional challenges, inherited traits and 
individual vulnerability to depressive symptoms among both sexes. Also, experiences of female adolescents as regards their exposure to sexual abuse which is taking a dangerous trend in southwest Nigeria and other social challenges might have possibly exposed them to more stress and vulnerability to depression than their male counterparts.

The study also revealed that counselling intervention would help to reduce the development of depressive symptoms and depression among adolescents. This is in agreement with researchers who have through the ages believed and propounded theories to establish the fact that counselling strategies, apart from the use of drugs, could be used for the treatment and prevention of depression. Among the notable approaches to understanding the causes and management of depression are the Freud's psychodynamic theory (Leuzinger-Bohleber, 2010), Beck's cognitive theory (Beck, 1967), Rational Emotive Behaviour Therapy (REBT) and Seligman's hopelessness theory (Abramson, Seligman \& Teasdale, 1978). Also, empirical studies attest to the effectiveness of counselling interventions in preventing, reducing and managing depression and depressive symptoms among adolescents (Lewinshon \& Clarke, 1999; Weisz, McCarthy \& Valeri, 2006; Stice, Shaw, Boho \& Marti, 2009). In essence, counselling intervention that is readily available would help to reduce and manage depression among in-school adolescents.

\section{RECOMMENDATIONS}

Based on the findings, it is recommended that:

1. School counsellors should organize programmes to create more awareness on adolescent depression. Understanding the concept of depression will assist the teachers and school authorities to distinguish depression from ordinary dejection and make them to provide assistance when necessary. School counsellors in conjunction with the school authorities can establish a depression awareness club especially in the rural areas where health facilities are not adequate. This will further enhance awareness of the risk factors, symptoms and consequences of depression among in-school adolescents.

2. Adolescents should be encouraged to discuss their challenges with the counsellors and their parents. Maintaining good rapport with them through provision of warm environment both in school and at home will encourage open line of communication that will help to reduce tension and development of depressive symptoms.

\section{References}

Abramson, L. Y., Seligman, M. E. P. \& Teasdale, J. (1978). Learned helplessness in humans: critique and reformulation. Journal of Abnormal Psychology, 87, 49-74.

Amato, P. R. (2001). Children of divorce in the 1990s: An update of the Amato and Keith (1991) Meta-analysis. Journal of Family Psychology, 15, 355-370. doi: 10.1037/08933200.15.3.355.

American Psychiatric Association (2013). Diagnostic and statistical manual of mental disorders (5th ed). Arlington, VA: American Psychiatric Publishing.

Barkmann, C., Romer, G., Watson, M., \& Schulte-Markwort, M. (2007). Parental physical illness as a risk for psychosocial maladjustment in children and adolescents: epidemiological findings from a National Survey in Germany. Psychosomatics 48: 226-236. doi: 10.1176/appi.psy.48.6.476.

Beck, A. T. (1967). Depression: Clinical, experimental and theoretical aspects. New York: Harper \& Row.

Bertha, E. A., \& Balazs, J. (2013). Subthreshold depression in adolescence: a systematic review. European Child \& Adolescent Psychiatry, 22, 589-603 
Ibimiluyi, F. O., Fasina, B. O. \& Iretor-Oscar, O. B. (2020) Influence Of Negative Life Events On Depression Among In-School Adolescents In Southwest Nigeria. Advances in Social Sciences Research Journal, 7(5) 430-439.

Brown, G. W., Bifulco, A. \& Harris, T. O. (1987). Life events, vulnerability and onset of depression: some refinements. British Journal of Psychiatry, 150, 30-42.

Deb, S., Strodi, E., \& Sun, J. (2014). Academic-related stress among private secondary school students in India. Asian Education Development Studies, 3, 118-134. doi/10.1108/AEDS-02-2013-0007

Farinde, A. (2013). The Beck Depression Inventory. The Pharma Innovation-Journal, 2(1), 5662. www.thepharmajournal.com>1.pdf. Retrieved on 22/1/2017

Farmer, A. E., \& McGuffin, P. (2003). Humiliation, loss and other types of life events and difficulties: a comparison of depressed subjects, healthy controls and their siblings. Psychological Medicine, 33, 1169-1175.

Fombonne, E. (1994). Increased rates of depression-updated of epidemiologic findings and analytical problems. Acta Psychiatr Scand, 90, 145-156.

Gesinde, A. M. \& Sanu, O. J. (2014). Prevalence and gender difference in self-reported depressive symptomatology among Nigerian university students: Implication for depressive counselling. The Counsellor, 33(2), 129-140. http://www.cassonnigeria.org/volume2014332.pdf. Retrieved 20/1/2017.

Hammen, C. (2005). Stress and depression. Annual Review of Clinical Psychology, 1, 293-319. https://dx.doi.org/10.1146/annurev.clinpsy.1.102803.143938. Retrieved on 22/1/17.

Hankin, B. L. (2006). Adolescent depression: Description, causes, and interventions. Epilepsy \& Behavior, 8, 102-114

Hanson, R. F., Self-Brown, S., Fricker-Elhai, A., Kilpatrick, D. G., Saunders, B. E., \& Resnick, H. (2006). Relations among parental substance use, violence exposure and mental health: the national survey of adolescents. Addict Behaviour, 31: 1988-2001. doi: 10.1016/j.addbeh.2006.01.012

Heim, C., Newport, D. J., Mletzko, T., Miller, A. H. \& Nemeroff, C. B. (2008). The link between childhood trauma and depression: insights from HPA axis studies in humans. Psychoneuroendocrinology, 33(6), 693-710. doi:10.1016/j.psyneuen.2008.03.008. www.ncbi.nlm.nih.gov/m/pubmed/18602762.

Herrenkohl, T. I., Kosterman, R., Hawkins, J. D., \& Mason, W. A. (2009). Effects of growth in family conflict in adolescence on adult depressive symptoms: mediating and moderating effects of stress and school bonding. Journal of Adolescence Health, 44: 146-152. doi: 10.1016/j.jadohealth.

Hofferth, S. L., \& Reid, L. (2002) Early childbearing and children's achievement and behavior over time. Perspect Sex Reproductive Health, 34, 41-49. doi: 10.2307/3030231

Hunter, J. \& National Institute of Mental Health (NIMH) (2013). Research on depression. PsychCentral. www.psychcentral.com/disorders/depressionresearch.htm.

Johnson, D. P., Whisman, M. A., Corley, R. P., John K. Hewitt, J. K., \& Rhee, S. H. (2012). Association between depressive symptoms and negative dependent life events from late childhood to adolescence. Journal of Abnormal Child Psychology, 40(8), 1385-1400. doi: 10.1007/s10802-012-9642-7

Kendler, K. S., Hettema, J. M., Butera, F., Gardner, C. O., \& Prescott, C. A. (2003). Life event dimensions of loss, humiliation, entrapment, and danger in the prediction of onsets of major depression and generalized anxiety. Archives of General Psychiatry, 60, 789-796.

Kendler, K. S., Kessler, R. C., Walters, E. E., MacLean, C., Neal, M. C., Heath, A. C. \& Eaves, L. J. (1995). Stressful life events, genetic liability, and onset of an episode of major depression in women. American Journal of Psychiatry, 152, $833-842$.

Kessler, R. C. (1997). The effects of stressful life events on depression. Annual Review of Psychology, 48, 191 -214.

Kim, E. K., \& Cain, K. C. (2008). Korean American adolescent depression and parenting. Journal of Child and Adolescent Psychiatric Nursing, 21(2), 105-115.https://doi.org/10.1111/j.1744-6171.2008.00137.x

Kio, J. O., Omeonu, P. E. \& Agbede, C. O. (2015). Assessment of stress levels among undergraduates in Nigeria: Implication for mental health policy. IOSR Journal of Nursing and Health Science, 4 (1) Ver. II ,1-8. www.iosrjournals.org/iosrjnhs/papers/vol4-issue1/Versio-2/C04121823.pdf. 
Leuzinger-Bohleber, M. (2010). Depression and trauma - a transgenerational psychoanalytical perspective. Keynote paper given at the First IPA Asian Congress in Peking,October 22, 2010.

www.sfifrankfurt.de/fileadmin/redakteure/pdf/03_Mitarbeiter_PDFs/03_Leuzinger Manuskripte/ML-B-Pekingpaper-2010.pdf

Lewinsohn, P. M. \& Clarke, G. N. (1999). Psychosocial treatment for adolescent depression. Clinical Psychology Review, 3, 329-342.

Ma, Y., Siu, A., \& Tse, W. S. (2018). The role of high parental expectations in adolescents' academic performance and depression in Hong Kong. Journal of Family Issues, 39(9), 2505-2522. Doi:10.1177/0192513X18755194.pdf

Moksnes, U. K., Espnes, G. A., \& Haugan, G. (2014). Stress, sense of cohence and emotional symptoms in adolescents. Psychology and Health, 29(1), 32 - 49. https://doi.org/10.1080/088704462013.822868

Monroe, S. M., \& Harkness, K. L. (2005). Life stress, the "kindling" hypothesis, and the recurrence of depression: considerations from a life stress perspective. Psychological Review, 112, 417-45.

Monroe, S. M., \& Reid, M. W. (2009). Life stress and major depression. Current Directions in Psychological Science. 18, 68-72.

Nolen-Hoeksema, S., Larson, J., \& Grayson, C. (1999). Explaining the gender difference in depressive symptoms. Journal of Personality and Social Psychology, 77, 1061 -1072.

Platt, B., Kadosh, K. C., \& Lau, J. Y. F. (2014). The role of peer rejection in adolescent rejection.Depressioon and Anxiety, 30(9), 809 - 821. https.//doi.org/10.1002/da.22120.pdf

Rutter, M., \& Quinton, D. (1984). Parental psychiatric disorder: effects on children. Psychological Medicine,14, 853880. doi: $10.1017 / \mathrm{s} 0033291700019838$

Ryba, M. M., Derek R. \& Hopko, D. R. (2012). Gender differences in depression: Assessing mediational effects of overt behaviors and environmental reward through daily diary monitoring. Volume 2012, Article ID 865679, 9 pages. http://dx.doi.org/10.1155/2012/865679

Schuster, R. M., Mermelstein, R., \& Wakschlag, L. (2013). Gender-specific relationships between depressive symptoms, marijuana use, parental communication and risky sexual behavior in adolescence. Journal of Youth Adolescence, 42(8), 1194-1209.

Siegel, J. M. (2002). Body image change and adolescent depressive symptoms. Journal of Adolescent Research, 17(1), 27-41. https://doi.org/10.1177/0743558402171002

Slavich, G. M., Monroe, S. M. \& Gotlib, I. H. (2011).Early parental loss and depression history: Associations with recent life stress inmajor depressive disorder. Journal of Psychiatric Research, 45, 1146-1152.

Slavich, G. M., O’Donovan, A., Epel, E. S., \& Kemeny, M. E. (2010a). Black sheep get the blues: a psychobiological model of social rejection and depression. Neuroscience and Behavioural Review,35(1), 39-45. www.ncbi.nlm.nih.gov/m/pubmed/20083138.

Stice, E., Shaw, H., Bohon, C. \& Marti, C. (2009). A meta-analytic review of depression prevention programs for children and adolescents: factors that predict magnitude of intervention effects. Journal of Consulting and Clinical Psychology, 77, 486-503.

Weisz, J., McCarthy, C. \& Valeri, S. (2006). Effects of psychotherapy for depression in children and adolescents: a metaanalysis. Psychological Bulletin, 132-149.

Weymouth, Buehler, Zhou, \& Henson (2016). A meta-analysis of parent-adolescent conflict: Disagreement, hostility, and youth management. Journal of Family Theory \& Review, 8(1), 95-112. Doi: 10.1111/jftr.12126

World Health Organization (WHO) (2010). Depression.

http://www.who.int/mental_health/management/depression/definition/en. WHO, 2010;

Zuckerbrot, R. A., Cheung, A., Jensen, P. S., Stein, R. E. K., Laraque, D., \& GLAD-PC STEERING GROUP (2018).Preparation, Identification, Assessment, and Initial Management. Pediatrics, 141 (3) e20174081; DOI: https://doi.org/10.1542/peds.2017-4081 